\title{
Impact of Laboratory-Based Instructional Intervention on the Learning Outcomes of Low Performing Senior Secondary Students in Physics
}

\author{
Isaac Ayodele Ojediran1, Daniel Idowu Oludipe ${ }^{2}$, Olusola Joseph Ehindero1 \\ ${ }^{1}$ Department of Special Education and Curriculum Studies, Faculty of Education, Obafemi Awolowo University, \\ Ile-Ife, Nigeria \\ ${ }^{2}$ Integrated Science Department, School of Science, Tai Solarin College of Education, Ijebu-Ode, Nigeria \\ Email: daniel.oludipe@gmail.com
}

Received 26 December 2013; revised 26 January 2014; accepted 4 February 2014

Copyright (C) 2014 by authors and Scientific Research Publishing Inc.

This work is licensed under the Creative Commons Attribution International License (CC BY). http://creativecommons.org/licenses/by/4.0/

(c) (i) Open Access

\begin{abstract}
This study investigated the impact of laboratory-based instructional intervention on the learning outcomes of low performing senior secondary students in Physics. The study adopted the pre-test and post-test control group quasi-experimental design. The treatments were at two levels (LBII and CTM). A total number of 194 SSS II students participated in the study. Physics Achievement Test (PAT) was the main instrument used to collect data from students. The data collected were analyzed using descriptive statistics and t-test, using SPSS 15.00 statistical packages at 0.05 level of significance. The results of this study indicated that there was significant difference in the achievement in Physics of low performing students exposed to laboratory-based instructional intervention (LBII) and those exposed to conventional teaching method (CTM). This study concludes that the use of laboratory based instructional intervention method of teaching should be embraced as a good asset to Physics Students and teachers in the senior secondary schools.
\end{abstract}

\section{Keywords}

Laboratory; Instructional-Intervention; Low-Performing; Senior Secondary Students; Learning Outcome

\section{Introduction}

Physics is the study of matter and natural events, based mostly on empirical observations and quantitative mea-

How to cite this paper: Ojediran, I. A., Oludipe, D. I., \& Ehindero, O. J. (2014). Impact of Laboratory-Based Instructional Intervention on the Learning Outcomes of Low Performing Senior Secondary Students in Physics. Creative Education, 5, 197-206. http://dx.doi.org/10.4236/ce.2014.54029 
surements. Many technical or basic tools and equipment surrounding us work according to the laws of physics. The results obtained from the scientific research have influenced the development of the areas in science and these new developments have been widely applied to daily life (Guzel, 2004). The knowledge of Physics is needed in the fields of medicine, nursing, pharmacy, agriculture, engineering and related disciplines. It is the subject that requires the processes of science to understand the theoretical concepts and their applications in solving practical problems encountered in everyday life. In Nigerian secondary schools, students study Physics for three years, i.e. Senior Secondary School one to three as stipulated in the National Policy on Education (FRN, 2004). During this period, teachers are required to engage students in practical works involving conducting experiments, with the aims of developing their scientific knowledge and experimental skills, and at the same time arousing and sustaining interest of the students in the subject as well as cultivating their attitude positively to Physics and Physics related phenomena. The importance attached to Physics by the Federal and State Governments in Nigeria has been clearly stated in section five of the revised version of the National Policy on Education (FRN, 2004). The inclusion of Physics as a core subject for science-bound students within the Nigerian education system calls for studies on how to teach it effectively. This is because effective Physics learning has both personal and societal values.

Different methods and strategies have been adopted to assist students in the process of learning and understanding Physics. Unfortunately, students still perform poorly in Physics at the West African School Certificate Examinations (Table 1), probably because many of them are yet to acquire the basic concepts and skills necessary for the learning and understanding the subject. The instructional methods and strategies commonly used in Physics classes targeted the average students. Students at risk who are low performing are yet to attract the attention of Physics-education researchers. As shown in Table 1, the number of the students at risk of low performing is swelling and calling for urgent attention. Reports of external examiners and personal experiences as classroom teacher show that students in physics lack some of the critical pre-requisite knowledge, skills, and techniques required to learn and understand concepts in physics. Among such pre-requisites are mathematical skills, language skill, and basic terminologies in physics. These areas are yet to attract the deserved attention of Physics education researchers. Therefore, Physics educators need to seek suitable teaching methods of tackling the current mass failure if they are to halt the drift of (low performing) student to arts and social science subjects. It has been observed that females constitute the bulk of the low performing Physics students. Hence, the imperative to focus on females in any instructional intervention strategy. This study therefore intends to examine how effective laboratory-based instructional intervention approach can assist students to acquire and use process skills in solving problems in Physics.

\section{Literature Survey}

Laboratory work is essential in the study of physics. The primary goals of introductory physics laboratories have been evolving over the past century. The current impetus for changes in laboratory instruction stems from new research on student learning and technology, as well as changes in the overall goals of physics instructors. The principle of Physics is stood on the test of all knowledge through experiment. Experiment is the sole judge of

Table 1. Trend of performance in physics in the west African school certificate examination May/June 2005-2011.

\begin{tabular}{cccc}
\hline YEAR & NO & \% CREDIT & \% FAIL \\
\hline 2005 & 15970 & $5047(31.60 \%)$ & $68.40 \%$ \\
2006 & 15947 & $6705(39.57 \%)$ & $60.43 \%$ \\
2007 & 17308 & $4865(28.10 \%)$ & $71.90 \%$ \\
2008 & 18239 & $5761(31.58 \%)$ & $68.42 \%$ \\
2009 & 18546 & $4877(26.30 \%)$ & $73.70 \%$ \\
2010 & 19440 & $5886(30.28 \%)$ & $69.72 \%$ \\
2011 & 18770 & $5327(28.38 \%)$ & $71.62 \%$ \\
\hline
\end{tabular}

Note: Source: West African Examination Council, 2011. 
scientific "truth". But what is the source of knowledge? Where do the laws that are to be tested come from? Experiment, itself, helps to produce these laws, in the sense that it gives us hints. But also needed is imagination to create from these hints the great generalizations - to guess at the wonderful, simple, but very strange pattern beneath them all, and then to experiment to check again whether we made the right guess. The laboratory should engage each student in significant experiences with experimental processes, including some experience, observation and investigation. For many students, an early experience with a stimulating scientific process in which they control the steps of an investigation can be a critical "turn-on" to physics and other sciences.

The laboratory should help the students develop a broad array of basic skills and tools of experimental physics and data analysis. While it is imperative that students have a broad experience with techniques using laboratory equipment, it is impossible to prescribe precisely which equipment should be used in all Physics laboratories. At the same time, it is advisable to allow students to make the use of many different types of laboratory apparatus to make observations. The laboratory should help students master basic physics concepts. A growing body of research in physics education indicates that a majority of students have difficulty in learning basic physical concepts in a course built around conventional teaching methods, textbook problems, and verification of experiments. These studies indicate that to improve learning, students must actively confront difficult concepts.

Effective learning may also be assisted by close interaction of students with their peers in this process. The laboratory can be an excellent environment for active learning. The laboratory has long been considered useful to develop conceptual understanding, but some recent courses have been developed that rely heavily on laboratory experience, in contrast to conventional teaching methods, for the development of conceptual understanding of physics. In such programs, conceptually oriented laboratory experiences may constitute a portion of the laboratory program, the entire laboratory program, or the entire course. The laboratory should help students understand the role of direct observation in physics and to distinguish between inferences based on theory and the outcomes of experiments. Physics is a complex structure of concepts, hypotheses, theories, and observations that are interrelated in such a way that it is often difficult to separate inferences based on theory from direct observations based on laboratory experiments. We should let the students understand that experimental evidence is the basis of their knowledge of the laws of physics and that physics is not merely a collection of equations and textbook problems.

The most important feature of effective Physics teaching is to support theoretical explanations with actual practices in the laboratory. The laboratory practices generally aim to improve the students' abilities by providing observation for conducting the experiments (Morgil, Gungor Seyhan, \& Secken, 2009). Laboratory activities have long had a distinctive and central role in Physics curriculum, and Physics educators have suggested that many benefits accrued from engaging students in Physics laboratory activities (Hosften \& Lunetta, 2004; Burke, Thomas, \& Brian, 2006). Also Leonard and Dufrense (1996) stressed that the use of inquiry approaches in college Physics laboratory courses provide evidence that such approaches involve students more and are more inductive than traditional approaches. He went further to say that the approaches provide less direction and therefore assign students more responsibility to determine procedural strategies and encourage students to make more use of Physics process skills. According to Leonard et al. (1996), inquiry approaches produce significantly greater educational gains than traditional laboratories and appear to work equally well for college students of all ability levels, not just the very academically talented, but also for the low performing among them who appear to be the majority of the student.

It was also reported that because students are using inquiry laboratory manual does not guarantee that students are doing inquiry or that the instructor is teaching using the inquiry process (Greenbowe \& Hand, 2005; Burke, \& Greenbowe, 2006). Herron and Nurrenbern (2005) cited in (Burke, Thomas, \& Brian 2006) Stated that, “inquiry-oriented laboratory activities teach inquiry better than lecture/demonstration or verification laboratory exercises, but only if teachers are skilled in inquiry teaching methods and students are given the time and guidance required to become comfortable with the new methods and expectations". Experiencing and understanding scientific phenomena and the scientific process are goals of most science laboratory courses. To achieve these goals, laboratory courses should provide opportunity for students to "restructure information" rather than simply be involved in verifying what they have been told. Students need to actively construct physics knowledge by being purposefully involved in posing questions, determining claims, and providing evidence (Thomas \& Brain, 2006).

Physics learning goals that have been attributed to laboratory experience includes: enhancing mastery of subject matter; developing scientific reasoning, understanding the complexity and ambiguity of empirical work, 
developing practical skills, understanding the nature of Physics, cultivating interest in Physics and interest in learning Physics; and developing teamwork ability in solving problems as stipulated in (National Research Council, 2006). It was also stated that no single laboratory experience is likely to achieve all these learning goals, different types of laboratory experiences may be designed to achieve one or more goals. Buntine, Read, Barrie, et al. (2007) stated that laboratory work is integral to bridging the gap between the molecular and macroscopic levels in Physics. Good laboratory programs provide a learning environment where physics students can forge links between theoretical concepts and experimental observations (Hegarty-Hazel, 1990).

In a well designed laboratory, students interact closely with teachers and peers, so that learning can be enhanced, monitored and assessed effectively (Psillos \& Niedderer, 2002 in Buntine et al., 2007). It has been recognized that a well-designed laboratory program for science, such as Physics, serves as a stimulant motivating students to learn. According to Hegarty-Hazel (1990), a well designed laboratory can be a popular component of Physics courses and can promote quality learning. Poorly designed laboratory exercises allow students to 'scaffold' each other's learning. Also when students were given a well designed laboratory exercise, they can experiment and engage, both individually and collaboratively, in open-ended labs and inquiry-based learning activities that apply theoretical concepts to relevant, real life problems. The aims of laboratory practices in Physics education have also been classified under four categories such as actualizing the conceptual learning, attaining technical skills, attaining research skills and producing effective learning products as suggested by (Lunette \& Hofstein, 1991; Hodson, 2001; Hegarty-Hazel, 1990; Woolnough, 1991).

Furthermore, laboratory experiments can help students to understand abstract concepts in Physics. Practical work is fun and interesting for the students. As a result of this, they are motivated to explore the material which related to the topics in the classroom. Practical work in the laboratory encourages students to approach problems and solve it, find the facts and new principles, develop ability to cooperate and develop critical attitude towards the subject. However, teachers' roles to help the students achieve these positive aims of practical work are very important. One of the teacher's roles is to create the positive learning environments in the laboratory to achieve the best education for the low performing Physics students. National Research Council (2006) stated that Physics can be enhanced when laboratory experiences provides opportunity to;

- pose a research question,

- use laboratory tools and procedures,

- make observations, gather and analyze data,

- verify, test, or evaluate explanatory models (including verifying known scientific theories and laws).

- formulate alternative hypotheses,

- design investigations, and

- build or revise explanatory models.

Nwosu and Okeke (1995) investigated the effect of guided-inquiry and demonstration methods of teaching process skills acquisition. The results revealed that students taught using the guided-inquiry method performed significantly better than those taught through demonstration and conventional methods. This is due to the fact that the guided inquiry method of teaching challenges students to be involved in the classroom. This method of teaching is activity-oriented rather than textbook or lecture-centered and it would help the students to acquire biology process skills needed for solving personal and societal problems. The result was basically on biology process skills not on Physics, while the majority of the Physics classes are academically disadvantaged.

Literature shows that process-oriented activities are not usually carried out in science (e.g. Physics classrooms in Nigeria). Obioha and Bomide (1986) reported that pupils are seldom confronted with first-hand concrete experiences which could allow them perceive relationships, predict events and draw conclusions. The reason for this, according to Ogunniyi (1986), includes lack of adequate laboratories and equipment, over-crowded classrooms, inappropriate teaching methods and the nature and pressure of external examinations. According to Okoye (2002), the problems militating against the advancement of Physics education include:

- lack of adequate textbooks;

- lack of funds to purchase equipment;

- overcrowded classroom/laboratory/time table;

- lack of cooperation by school administrators;

- the pressure of external certificate examinations;

- lack of proper monitoring and feedback mechanism;

- poor preparation of teachers who teach new programs; 
- lack of motivation among teachers;

- rapid rate at which teachers are transferred from one school to another or out of the profession;

- the use of archaic teaching methods;

- poor implementation procedure;

- overwhelming number of activities demanded by the new curricula;

- shortage of qualified teachers;

- lack of clear-cut goals;

- scanty research reports on the performance of the programs;

- prevalence of superstitious beliefs; and

- general lack of reinforcing home environments.

Intervention is a situation in which someone becomes involved in a particular issue or problems in order to influence what happens as stipulated in Macmillan (2007). Instructional interventions are generally meant to maximize learning gain as posited by Ulrike and Robin (2004). Hodson (1993) emphasized that the principal focus of laboratory intervention should not be limited to learning specific scientific methods or particular laboratory techniques; instead, student in the laboratory should use the methods and procedures of science to investigate phenomena, solve problems, pursue inquiry and interests. Interest in using inquiry-based teaching strategies has increased in recent years as science teachers have become more critical about the efficacy of cookbook-type laboratory activities and indeed the purpose, practices, and learning outcomes of laboratory in general (Wellington, 1998). It is gradually being recognized that where as cookbook laboratory can teach some laboratory techniques and skills (Hart, Mulhall, Berry, Loughran, \& Gunstone, 2000) or serve as visual aids for concept already studied (Millar, 1998), they are largely ineffective as a tool for teaching science concept.

The teaching should aim at developing in the students the process skills necessary to make him/her be competent and confident in the investigations of the material resources around him/her. Laboratory based instructional intervention is inquiry based teaching which encourage learners to become more involved in a particular tasks in an enabling and conducive environment where all the equipment needed to perform a specific task is abundantly available for the learner to interact with. Therefore, laboratory based instructional intervention are all learning experiences in which students interact with relevant materials and/or with models to observe and understand the natural world. It appears that low performing students have not been grounded in laboratory activities that can prepare them to solve problems in Physics that will improve their performances. In addition, it will appear that this inability is related to their attitude to Physics activities in general. A laboratory-based instructional intervention in Physics that combines both problem solving skills, mathematical skills (such as measurement, ratio, proportion) and attitude to laboratory work is likely to improve performance in Physics of low performing students.

Adesoji (2008) investigated students' ability levels and effectiveness of problem-solving instructional strategy. He reported that there is disparity in the ability to perform specific tasks. In his word, he stressed that all aspects of Physics could be said to be problem solving and students have varying ability when they are confronted with problems to solve (Adesoji, 1992). He also emphasized the view of Salami (2000) that problem solving in Physics depends on students cognitive ability level which differentiate between the high performing and low performing students in Physics in Nigerian secondary schools. Several studies within the Nigeria environment have, however, shown that learners are qualitatively different in their performance levels and in learning problems (Usua, 1974; Ehindero, 1980). Some studies also reported that methods of instruction can influence the performances of low achieving students (Kempa \& Dube, 1974; Long et al., 1981; Adesoji, 1992; Okebukola, 1992; Lavioe, 1993; Ireogbu, 1998). However, performance of low performing students has been found to be lowest while that of the high performing students was the highest (Kempa \& Dube, 1974). It has also been observed that problem solving strategies were effective in teaching students of different performance level (Adesoji, 1997).

Mari (2002) investigated gender related differences in acquisition of formal reasoning: pedagogic implication of teaching Chemistry using process-based approach. The findings showed that the initial gap between the male and female subjects in formal reasoning ability was bridged in all the Schemata (Conservation, Control of variables, proportional reasoning, probability reasoning, and combinatorial reasoning) except in correlation reasoning. This is due to the fact that the process-based instruction tends to have stimulated higher reasoning gains in the female subjects than the male subjects. There is, therefore, the need to use Physics process-based instruction in the early years in secondary school as a means to reduce, if not totally eliminate, the male/female differ- 
ence in reasoning ability. Njoku (2002) determined the effects of mixed-sex and single-sex grouping strategies in co-educational classrooms on girls' acquisition of Physics process skills. The results showed that girls in single-sex group scored significantly higher mean in Physics process skills than girls in mixed-sex group. The differences in achievement may have originated from the differential opportunity to engage in learning tasks. It is possible for boys in the mixed-sex group to deny the girls of participating in most of the activities during teaching and learning process because the boys always claim to be superior to the girls and as a result of this, they normally dominate the group and this could lead to a better performance of the boys than the girls in the group.

Conventional Teaching Method is a "one-way traffic" type of classroom interaction in which the teacher talks and writes notes on the board while the students listen and copy down notes. Students' participations are minimal and they are not given the opportunity to give a feedback to the teacher. This method has been reported not supporting academic achievement of low performing students.

\section{Hypothesis}

$\mathrm{Ho}_{1}$ : There is no significant difference in the achievement in Physics of low performing students exposed to LBII and those exposed to CTM.

$\mathrm{Ho}_{2}$ : There is no significant difference in the achievements of low performing male and female students in Physics exposed to LBII and those exposed to CTM.

\section{Research Methods}

\subsection{Participants}

The study population comprised Senior Secondary Two (SSS II) Physics students in Osun state. Two senatorial districts were randomly selected from the total number of senatorial districts in Osun state. Two co-educational senior secondary school II were purposefully selected based on availability of well equipped Physics laboratory from each senatorial district. A total of 194 students, who scored below 40\% in the previous Physics promotion examination from SSS I to SSS II in the purposefully selected schools, were classified to be low performing students, and thus, were used for the study. The schools were randomly assigned to the experimental and the control groups.

\subsection{Materials}

The instructional package consists of topics that require solving numerical problems in Physics involving hook's law and ohm's law. Two instruments were developed for use in the study. They were Physics Achievement Test (PAT), and Assessment of Students Science and Mathematics Process Skills in the Laboratory (ASSSMPSL) which were used for both pretest and post-test. The PAT items were selected from West African Examination Council (WAEC) and National Examination Council (NECO) past examination questions respectively. The PAT was used to assess student's achievement in Physics. It consisted of 25 multiple choice objective test items on Hook's law and Snell's law. The items in PAT instrument are standardized in nature because they have been field-validated by the experienced test and measurement experts in WAEC and NECO respectively. Moderating committee of the aforementioned examination bodies edited and selected good items. The second instrument used was Assessing Student Science and Mathematics Process Skills in the Laboratory (ASSSMPSL).

\subsection{Procedure}

The researchers identified 9 science and mathematical process skills which comprises arrangement of apparatus, observing, measuring, recording, hypothesizing, deducing, reporting; while that of mathematical skills including proportionality and ratio. Both face and content validity were undertaken by a lecturer in test and measurement and two experienced Physics teachers in senior secondary schools, who are seasoned examiners of WAEC and NECO, for comments on validity and correctness of the questions and options. The draft of ASSSMPSL was given to two experts in Tests, Measurement and Evaluation to comment on the items in terms of relevance, sentence structure and adequacy of the instrument. Based on their recommendations, the items were accepted for the process. The reliability of the ASSSMPSL was tested on six low performing Physics students in two schools for consistencies. Pearson's Product Moment correlation formula and then Spearman Brown formula (Split-half 
method) were used for correction. The reliability coefficient was calculated to be 0.66 . Two research assistants used for the treatment group were trained for two days by the researchers on how to present LBII to students in the laboratory during the third term holiday in August, 2011. The Physics teachers also received curriculum materials for Laboratory-Based Instructional Intervention in Physics as training materials by the researcher. The data collected were analyzed using descriptive statistics, and t-test using SPSS 15.00 statistical packages at 0.05 level of significance.

\section{Results and Discussion}

\subsection{Results}

Hypothesis $1\left(\mathrm{Ho}_{1}\right)$ :

There is no significant difference in the achievement in Physics of low performing students exposed to LBII and those exposed to CTM.

Pair wise comparison, as shown in the Table 2, using independent samples t-test, showed that while there was no significant difference in students physics scores between the LBII and CTM groups in the pre-training test, $t_{(192)}=.009, p>.05$, there was a significant difference in the post-training test score, $t_{(192)}=5.42, p<.05$ (2-tailed).

Hypothesis $2\left(\mathrm{HO}_{2}\right)$ :

There is no significant difference in the achievement of low performing male and female students in physics after being exposed to LBII

Table 3 presents the mean achievement scores of male and female students in physics before and after exposure to LBII. Pair wise comparison of the means, using independent sample t-test, showed that while there was no significant difference in the performance of low performing male and female students in physics before exposure to LBII $\left(\mathrm{t}_{(110)}=.90, p>.05\right)$, the difference that was noticed in their performance after the exposure to LBII is significant $\left(\mathrm{t}_{(110)}=2.15, p<.05\right)$. The significant difference, as noticed in Table 3 , indicates that the female students significantly perform better than the male students after the treatment. Thus it is most likely that the use of the LBII assisted the female students to have significantly better achievement in physics.

\subsection{Discussion}

The findings of this study show that there was a significant difference in the achievement in Physics of low

Table 2. Summary of t-test showing the difference in the performance of low performing students in physics before and after exposure to LBII and CTM.

\begin{tabular}{lccccccc}
\hline & Experimental Groupings & $\mathrm{N}$ & Mean & SD & T & $p$ \\
\hline \multirow{3}{*}{ Students' Pre-Test Scores } & LBII Group & 112 & 9.5089 & 2.30938 & & \\
& CTM Group & 82 & 10.4756 & 3.78504 & & \\
& LBII Group & 112 & 13.5179 & 2.99844 & & \\
Students Post-Test Scores & CTM Group & 82 & 11.4146 & 3.20860 & & \\
\hline
\end{tabular}

Table 3. Summary of t-test showing the difference in the performance of male and female low performing students in physics before and after exposure to LBII.

\begin{tabular}{ccccccc}
\hline & Sex & $\mathrm{N}$ & $\bar{X}$ & $\mathrm{SD}$ & $\mathrm{T}$ & $p$ \\
\hline \multirow{2}{*}{ LBII PRE } & Male & 53 & 9.3019 & 2.30872 & & \\
& Female & 59 & 9.6949 & 2.31378 & .90 & $>.05$ \\
& Male & 53 & 12.8868 & 2.67222 & & \\
LBII POST & Female & 59 & 14.0847 & 3.18015 & & $<.05$ \\
& & & & & \\
\hline
\end{tabular}


performing students exposed to laboratory-based instructional intervention (LBII) and those exposed to conventional teaching method (CTM). It is concluded that the LBII technique is effective in improving the performance of low performing as well as average Physics students in Physics. The difference might be due to the opportunity the student taught under LBII had by interacting with the materials provided under strict supervision by the teacher. This suggests that when learning is activity-based, students learn and retain what they learn more and in the end perform better.

Along gender line, Table 3 also shows that female students significantly perform better than the male students after the treatment. This is a pointer to the fact that gender is effective on science achievement dates back to very old times, and this is because women missed role in science in the past. However, this assertion is proposed with many studies that males do better in science courses than females do (Guzel, 2004). One possible reason for female performance is that they are more careful with handling of equipment, less time wasted and better organizational skills, while the over confidentiality of the male counterpart at the beginning of the study made them to be more wasteful and not performing as expected. Females attend more to details in and within experimental settings. Therefore, today's women are more successful in science than they were in the past.

Finding of this study also reveal that there was tremendous increase in acquisition of science and mathematics process skills of low performing Physics students in the laboratory after exposing them to LBII. This may be due to many practices the students had in carrying out the experiments. This emphasizes that expertise in science process skills is not innate, but acquired through constant practice and interaction with curriculum materials.

\section{Conclusion and Recommendations}

This study concludes that the use of laboratory based instructional intervention method of teaching should be embraced as a good asset to Physics Students and teachers in the senior secondary schools. Based on the findings of this study and conclusion reached, the following recommendations were made that:

1) Physics teachers should be encouraged to adopt laboratory based instructional intervention method as an effective learning strategy to enhance the performance of low performing students in and influence their attitude towards Physics.

2) Laboratory-based instructional intervention should be used in teaching various concepts in Physics starting from senior secondary school and continuing in tertiary institutions.

3) Physics students at senior secondary schools level should be given the opportunity to handle and manipulate materials, tools and equipment in the laboratories.

4) Effective use of this method to teach physics can provide students with low performance in Physics the opportunity to participate in the activities and maximize individual potentials in learning the subject.

5) Emphasis in Physics practical should focus on the core processes of learning incorporated in the laboratorybased strategies used in this study.

6) More females students should be encouraged to enroll in Physics classes and teachers should target them for guidance as females have qualities which can enhance their acquisition of Physics concepts.

\section{Competing Interests}

Authors have declared that no competing interests exist.

\section{Funding}

This work was carried out in collaboration among OJE, IAO, and ODI. OJE handled the theoretical literature review on the topic and designed the study. IAO handled the empirical literature review on the topic. ODI performed the statistical analysis of the data collected.

\section{References}

Adesoji, F. A. (1992). A Comparative Analysis of Problems Solving and Self Learning Techniques in Teaching Electrolysis. Unpublished PhD Thesis, Ile-Ife: Obafemi Awolowo University.

Adesoji, F. A. (1997). Average Students and Effectiveness of Problems Solving Instructional Strategies. Ife Journal of Educational Studies, 4.

Adesoji, F. A. (2008). Students Ability Levels and Effectiveness of Problem—Solving Instructional Strategy. Journal of So- 
cial Physics, 17, 5-8.

Buntine, M. A., Read, J. R., Barrie, S. C., Bucat, R. B., Crisp, G. T., George, A. V., Jamie, I. M., \& Kable, S. H. (2007). Advancing Chemistry by Enhancing Learning in the Laboratory (ACELL): A Model for Providing Professional and Personal Development and Facilitating Improved Student Laboratory Learning Outcomes. Journal of Chemistry Education Research and Practice, 8, 232-254. http://dx.doi.org/10.1039/b6rp90033j

Burke, K. A., \& Greenbowe, T. J. (2006). Heuristic in the Chemistry Laboaratory. Journal of Chemical Education, 83, 10321038. http://dx.doi.org/10.1021/ed083p1032

Burke, K. A., Thomas, J. G., \& Brian, M. H. (2006). Implementing the Physics Writing.

Ehindero, O. J. (cited from Oyekan, S. O.) (1980). Cognitive Styles, Sex and Achievement in Biology. Journal of Education and Society, 2, 141-152.

Federal Republic of Nigeria (FRN) (2004). National Policy on Education. Lagos: NERDC Press.

Greenbowe, T. T., \& Hand, B. M. (2005). Introduction to the Physics Writing. In N. P. Pienta, M. M. Cooper, \& T. J. Greenbowe (Eds.), Chemists’ Guide to Effective Teaching. Upper Saddle River: Prentice Hall.

Guzel, H. (2004). The Relationship Between Students Success in Physics Lessons and Their Attitudes towards Mathematics. Journal of Turkish Science Education, 1, 1-2.

Hart, C., Mulhall, P., Berry, A., Loughran, J., \& Gunstone, R. (2000). What Is the Purpose of This Experiment? Or Can Students Learn Something from Doing Experiments? Journal of Research in Science Teaching, 37, 655-675. http://dx.doi.org/10.1002/1098-2736(200009)37:7<655::AID-TEA3>3.0.CO;2-E

Hegarty-Hazel, E. (1990). The Student Laboratory and the Science Curriculum: An Overview. In E. Hegarty-Hazel (Ed.), The Student Laboratory and the Science Curriculum (pp. 3-26). London: Routledge.

Hodson, D. (1993). Re-Thinking Old Ways: Towards a More Critical Approach to Practical Work in School Science. Studies in Science Education, 22, 85-142. http://dx.doi.org/10.1080/03057269308560022

Hofstein, A. (2004). The Laboratory in Chemistry Education: Thirty Years of Experience with Developments, Implementation, and Research. Chemistry Education: Research and Practice, 5, 247-264.

Ireogbu, Y. O. (1998). Problem-Based Learning, Numerical ability and Gender as Determinants Achievement in Line Graphing Skills and Meaningful Learning in Energy Concepts. Unpublished Ph.D. Thesis, Ibadan: University of Ibadan.

Kempa, R. F., \& Dube, C. E. (1974). Physics Interest and Attitude Traits in Students' Subsequent to the Study of Chemistry at the Ordinary Level of the G.C.E. Journal of Research in Physics Technology, 11, 361-370.

Lavioe, D. R. (1993) The Development, Theory and Application of Cognitive Network Model of Prediction of Cognition Network Model of Prediction Problem Solving in Biology. Journal of Research in Physics Teaching, 30, 767-785. http://dx.doi.org/10.1002/tea.3660300713

Leonard, W. L., Dufrense, R. J., \& Mester, J. P. (1998). Using Quantitative Problem-Solving Strategies to Highlight the Role of Conceptual Knowledge in Solving Problems. American Journal of Physics, 64, 1495-1503.

http://dx.doi.org/10.1119/1.18409

Lunette, V. N., \& Hofstein (1991). Simulation and Laboratory Practical Activity. In B. E. Woolnough (Ed.), Practical Science (pp. 125-137). Milton Keynes: Open University Press.

Long, J. C., et al. (1981). The Effect of a Diagnostic-Prescriptive Teaching Strategy on Student's Achievement and Attitude in Biology. Journal of Research in Physics Teaching, 30, 515-523. http://dx.doi.org/10.1002/tea.3660180606

Macmillan (2007). Macmillan English Dictionary for Advanced Learners. A\&C Black Publishers LTD. Oxford.

Mari, J. S. (2002). Gender Related Differences in Acquisition of Formal Reasoning Approach. Journal of the Physics Teachers' Association of Nigeria, 37, 76-81.

Meltem, D., \& Oguz, O. (2010). The Effects of Scientific Process Skills.

Millar, R. (1995). A Means to an End: The Role of Processed in Physics Education. In B. Wodnough (Ed.), Practical Physics. Milton Keynes, Philadelphia: Open Universities Press.

Morgil, I., Gungor, S. H., \& Secken, N. (2009). Investigating the Effects of Project-Oriented Chemistry Experiments on some Affective and Cognitive Field Components. Journal of Turkish Physics Education, 6, 108-114.

National Research Council (2006). Americas’ Lab. Report: Investigations in High School Physics. Washington, DC: National Academy Press. www.nap.edu

Njoku, Z. C. (2002). Enhancing Girls’ Acquisition of Physics Process Skills in Co-educational Schools: An Experience with Sex Grouping for Practical Chemistry. Journal of Physics Teachers' Association of Nigeria, 37, 69-75.

Nwosu, A. A., \& Okeke, E. A. C. (1995). The Effect of Teacher Sensitization of Students’ Acquisition of Science Process Skills. Journal of Science Teacher Association Nigeria, 30, 39-45. 
Obioha, N. E., \& Bomide, G. S. (1986). Concept Development and Physics Achievement among Junior High School Students. 27th Science Teachers’ Association of Nigeria (STAN) Annual Conference Proceedings, 295-301.

Ogunniyi, M. B. (1986). Teaching Physics in Africa. Ibadan: Salem Media.

Okebukola, P. A. O. (1992). Can Good Concept Mappers Be Good Problem Solvers? Education Psychology, 12, 113-129. http://dx.doi.org/10.1080/0144341920120203

Psillos, D., \& Niedderer, H. (2002). Teaching and Learning in the Physics Laboratory. Physics and Technology Education Library, Dordrecht: Kluwer Academic Publishers.

Salami, I. O, (2000). Effect of Three Instructional Models of Students Teachers' Performance in Selected Teaching Skills. Unpublished Ph.D. Thesis, Ibadan: University of Ibadan.

Ulric-Marie, K., \& Robin, S. (2004). Too Much of a Good Thing? Unwanted Side Effects of Successful Instructional Intervention.

Usua, A. (cited from Oyekan, S. O.) (1994). Cognitive Styles, Sex and Achievement in Biology. Journal of Education and Society, 1, 10.

Wellington, J. (1998). Practical Work in School Science: Which Way Now? In Routledge (Ed.), London.

Woolnoungh, B. E. (1994). Why Students Choose Physics or Reject It. Physics Education, 29, 368-374.

http://dx.doi.org/10.1088/0031-9120/29/6/006 